\title{
Comparing Resident Outcomes in Cataract Surgery at Different Levels of Experience
}

This article was published in the following Dove Press journal:

Clinical Ophthalmology

\author{
Mathias $\vee$ Melega $\mathbb{I}^{\prime}$ \\ Rodrigo Pessoa Cavalcanti Lira ${ }^{2}$ \\ luri Cardoso da Silva' \\ Bruna Gil Ferreira' \\ Hermano LG Assis Filho' \\ Alexandre AF Martini' \\ Roberto dos Reis' \\ Carlos Eduardo Leite Arieta (ID) \\ Monica Alves' \\ 'School of Medical Sciences, \\ Ophthalmology Department of \\ University of Campinas (UNICAMP), \\ Campinas, São Paulo, Brazil; ${ }^{2}$ School of \\ Medical Sciences, Ophthalmology \\ Department of Federal University of \\ Pernambuco (UFPE), Recife, Pernambuco, \\ Brazil
}

Correspondence: Mathias V Melega School of Medical Sciences, University of Campinas (UNICAMP), Rua Dona Josefina Sarmento 120, Ap 7I, Cambuí, Campinas, SP CEP 13025-260, Brazil Tel +55 19997513150

Email mvmelega@hotmail.com
Purpose: To evaluate outcomes of resident-performed cataract surgeries in different training levels in a retrospective case series.

Patients and Methods: A total of 730 surgeries performed by residents were evaluated into three groups: surgeries performed during residents' first semester of training in phacoemulsification (Level 1 - L1), surgeries performed during the second semester (Level 2 - L2), and surgeries performed during the third semester (Level $3-\mathrm{L} 3$ ). The primary outcome was the incidence of intraoperative complications in each group. Secondary outcomes were the comparisons between initial and final corrected distance visual acuity (CDVA), intraocular pressure (IOP), endothelial cell density (ECD), and central corneal thickness (CCT) in each group. Descriptive statistical analyses were employed in the presentation of the results using central tendency and variance measurements.

Results: The rate of complications within six weeks of follow-up was 24 out of 102 eyes (23.53\%) in the L1 group, 63 out of 301 eyes (20.93\%) in the L2 group, and 37 out of 327 $(11.31 \%)$ in the L3 group ( $p=0.001)$. Posterior capsule rupture (PCR) was the most frequent intercurrence observed in all three semesters: it occurred in $12.7 \%$ of the surgeries in the first semester (13/102), $16.9 \%$ of surgeries in the second semester $(51 / 301)$, and $9.5 \%$ of surgeries in the third semester (31/327). There was no significant difference in CDVA $(p=0.298)$, ECD ( $p=0.067)$, IOP $(p=0.217)$, or CCT $(p=0.807)$ between the groups.

Conclusion: When measured by rates of complications and by the aforementioned parameters, surgical competency was found to improve as surgical experience and frequency increased. Therefore, this study identified some patterns of skill development that can be applied to teaching strategies and better assist surgeons in training.

Keywords: cataract, phacoemulsification, complications, practicing surgeons, surgical education, ophthalmology residency

\section{Introduction}

Cataract surgery, which consists of the removal of the opaque lens and subsequent implantation of an intraocular lens, is one of the most commonly performed surgeries worldwide. For these reasons, a large part of ophthalmology residents' training is focused on cataract surgery. The current surgical approach to guarantee best outcomes is phacoemulsification, but this technique is mastered on a learning curve affected by increased familiarity with the equipment and the development of surgical skills. ${ }^{1-3}$

Medical residency programs around the world have debated the best approaches to properly teach and better train residents in such important surgical techniques. ${ }^{4-9}$ Different methods have been used to evaluate surgical learning curves among 
medical residents. Most authors have defined the rate of success by final surgical outcomes; in the case of cataract surgery, these outcomes include patients' final visual acuity and the rate and type of complications. ${ }^{10-12}$ Endothelial cell loss is a recognized risk of cataract surgery. Although phacoemulsification is a safe procedure, the risk of endothelial cell loss is inherent due to the intraocular maneuvers involved. ${ }^{13-18}$

In this study, surgical outcomes in surgeries performed by a group of 10 ophthalmology residents at the University of Campinas (UNICAMP) over the course of 18 months of phacoemulsification training (July 2016 to January 2018) were compared. We retrospectively analyzed intraoperative complications, as well as pre-, intra-, and postoperative parameters, in order to compare outcomes among residents of different training levels. The parameters used were patients' corrected distance visual acuity (CDVA), intraocular pressure (IOP), endothelial cell density (ECD), and central corneal thickness (CCT), which were measured before and 6 weeks after surgery. Previous studies on learning curves for phacoemulsification surgery have measured rate of complications. ${ }^{11}$ The aforementioned parameters are also highly relevant but rarely considered in studies of ophthalmology residents' surgical skills and have therefore been included in this study to better support any conclusions regarding the impact of surgeon experience on outcomes. ${ }^{2-8,10,13,14}$

\section{Patients and Methods}

This study was a single-site retrospective case series. It was performed after approval from the local research ethics committee (University of Campinas Ethics Committee) and was conducted in accordance with the tenets of the Declaration of Helsinki and current legislation on clinical research. The inclusion criteria were the indication of phacoemulsification and at least 40 years of age. Our residency program requires that more difficult surgeries, such as those involving small pupils, dense cataracts, zonulopathy, Fuchs' dystrophy and traumatic cataracts, be performed by a fourth-year resident, who is, by definition, a cataract fellow, as well as under an attending surgeon's supervision. Therefore, surgeries included this study involved all the cases of cataracts without other factors that could increase the degree of difficulty, and the surgeries were equally distributed among the three groups. The exclusion criteria were, signs of ocular or periocular infection, advanced glaucoma and severe ocular surface disease, and cataract surgery associated with other concomitant procedures, such as glaucoma filtering surgery, vitreoretinal surgery, or corneal surgery. There were no exclusions of surgeries with unfavorable outcomes.

Data were collected from patients undergoing cataract surgery at UNICAMP Clinical Hospital. Medical records, preoperative routine clinical exams, intraoperative descriptions and data from the first, seventh, thirtieth, and forty-fifth postoperative days were collected on each patient. Data were obtained from medical records that were completed on the day of surgery and during each scheduled follow-up appointment by the resident and the attending surgeon. Comprehensive protocols for cataract surgery data collection have been created and used in our department in order to thoroughly and objectively record information on all variables involved in the surgical procedure, as well as in the pre- and postoperative periods. To avoid the risk of recall bias inherent to retrospective studies, only data from these medical records have been included herein.

CDVA, IOP, ECD, and CCT were obtained for all included patients prior to surgery and at the last followup appointment ( 6 weeks after surgery). Although uncommon, variations in IOP and CCT can be considered indirect indicators of both surgical trauma to the trabecular meshwork and a loss of corneal endothelial cells, respectively.

In accordance with the protocols used in the Department of Ophthalmology of the University of Campinas (UNICAMP), all cataract surgeries are performed by ophthalmology residents and a senior attending surgeon with substantial experience in cataract surgery, regardless the level of the resident's training. The attending surgeon provides residents with verbal instructions during the surgical procedure, and if the resident is unable to perform a specific surgical step or in cases of complications, the supervisor takes over the surgery, demonstrating how to solve that step. Variations and preferences between surgeons performing cataract surgery, such as the choice of incision position or the phacoemulsification technique used, are accepted in our department. However, surgical protocols, instrumentation, and techniques are standardized, as are all intraoperative drugs, solutions, ophthalmic devices, blades, and IOLs. All surgeries were performed with peribulbar anesthesia. Phacoemulsification using the Infiniti ${ }^{\circledR}$ or the Laureate $^{\circledR}$ phacoemulsifier (Alcon Laboratories Inc, Fort Worth, Texas, USA) was performed, and an AcrySof $^{\circledR}$ intraocular foldable lens (Alcon Laboratories Inc, Fort Worth, Texas, USA) was implanted. A clear corneal incision was used. The phacoemulsification technique 
was either the stop and chop or the phaco chop. Intracameral moxifloxacin (Vigamox ${ }^{\circledR}$ ) was injected as the final step of the surgery $(150 \mu \mathrm{g}$ in $0.03 \mathrm{~mL}) .{ }^{19}$ In the immediate postoperative period, patients received $0.5 \%$ moxifloxacin and $0.1 \%$ dexamethasone eye drops prior to bandaging. Similarly, the topical postoperative regimen consisted of $0.5 \%$ moxifloxacin combined with $0.1 \%$ dexamethasone every 3 hours for 7 days only during waking hours. On the seventh postoperative day, this regimen was changed to only $0.1 \%$ dexamethasone, which was tapered over the course of 3 weeks. In cases of intraoperative or postoperative complications, patients received appropriate follow-up care in the Department of Ophthalmology at UNICAMP and underwent all necessary treatment.

A series of parameters were compared in order to better characterize the learning curve among ophthalmology residents at UNICAMP. These parameters included rates of complications and reinterventions, as well as previous and final CDVA, IOP, ECD, and CCT. The most common intraoperative complications include posterior capsule rupture (PCR), vitreous loss, aphakia, dropped nucleus, incision burn, Descemet's membrane detachment, iris herniation, Argentinian flag sign, zonular dehiscence.

In the Department of Ophthalmology of UNICAMP, the training protocol for cataract surgery is as follows: in the first year, residents learn from theory, surgery simulation, and assisting attending surgeons. In the first semester (the first 6 months) of the second year of program, residents learn extracapsular cataract extraction (ECCE) and learn the first steps of phacoemulsification. In the second semester of the second year onward, they practice phacoemulsification under the supervision of a senior surgeon until the end of the third year of the residency program. The residents' phacoemulsification practice is thus spread out over three consecutive semesters, and the surgeries included herein were therefore divided into those performed during residents' first semester of training in phacoemulsification (the Level 1 - L1 Group, which represents the last 6 months of the second year of residency), those performed during the second semester of training (the Level 2 - L2 Group, which represents the first 6 months of the third year of residency), and those performed during the third semester (the Level 3 - L3 Group, which represents the last 6 months of the third year of residency). The surgeries were included based on a convenience sample of patients who completed 45 weeks of follow-up care after undergoing phacoemulsification surgery performed by a group of ten residents over the course of eighteen months (from July 2016 to January 2018).

Initial and final CDVA, IOP, ECD, CCT, and intraoperative events were recorded and compared.

\section{Statistical Analysis}

Descriptive statistical analyses were employed in the presentation of the results using central tendency and variance measurements. The groups' continuous variables were compared using the $t$-test or ANOVA (parametric variables) or the Mann-Whitney or Kruskal-Wallis tests (non-parametric variables). Statistical analyses of the categorical variables were performed using Fisher's exact test or the chi-squared test. Analyses were performed using STATA 14.0 (StataCorp LP, College Station, TX, USA). Statistical significance was established when $p \leq 0.05$.

\section{Results}

A total of 730 surgeries performed by the same group of 10 residents were included in the study. One hundred and two surgeries were included from the first semester of phacoemulsification training (L1), 301 surgeries were included from the second semester (L2 Group), and 327 surgeries were included from the third semester (L3 Group).

Preoperative demographic data demonstrated homogeneity between the groups, as displayed in Table 1.

The mean change in CDVA, ECD, IOP, and CCT from baseline to the evaluation 6 weeks after cataract surgery may reflect the safety of the procedure. Table 2 displays this data according to the level in the surgeon's training, with no significant differences between the three groups.

The absolute numbers were compared between the three study groups, with a marked improvement in CDVA along with a loss of endothelial cells in all three groups. There was no difference between the pre- and postoperative CCT or IOP values ( $\mathrm{p}>0.05$ ).

There was no significant difference between pre- and postoperative variation in CDVA $(\mathrm{p}=0.29)$, IOP $(\mathrm{p}=$ 0.22), ECD (0.06), or CCT between Groups L1, L2 and L3 $(p=0.80)$. However, a clear decrease in endothelial loss over the course of the semesters was observed.

Table 3 presents the frequencies of intraoperative complications in each group, with an emphasis on posterior capsule rupture (PCR) with vitreous loss.

Multiple logistic regression was used to evaluate the association between intraoperative events per group, which 
Table I Preoperative Demographic Data on the Cataract Surgery Patients Allocated to Each Semester Group

\begin{tabular}{|l|l|l|l|l|}
\hline & First Semester $(\mathbf{n}=102)$ & Second Semester $(\mathbf{n}=301)$ & Third Semester $(\mathbf{n}=327)$ & $\boldsymbol{p}$-value \\
\hline Sex (female/male; \%) & $42.16 / 57.84$ & $47.18 / 52.82$ & $49.85 / 50.15$ & $0.388^{*}$ \\
Age (in years) & $70.29 \pm 7.67$ & $69.78 \pm 8.97$ & $68.39 \pm 9.57$ & $0.176^{\dagger}$ \\
CDVA (ETDRS score) & $57.49 \pm 1.58$ & $59.97 \pm 0.98$ & $58.22 \pm 82.37$ & $0.25 I^{\dagger}$ \\
ECD (cells/mm $\left.{ }^{2}\right)$ & $2388.18 \pm 26.65$ & $2348.25 \pm 20.66$ & $2344.12 \pm 18.04$ & $0.266^{\dagger}$ \\
IOP $(\mathrm{mmHg})$ & $13.72 \pm 0.33$ & $13.68 \pm 0.21$ & $14.20 \pm 0.19$ & $0.082^{\dagger}$ \\
CCT $(\mu \mathrm{m})$ & $537.30 \pm 4.52$ & $534.74 \pm 2.67$ & $538.42 \pm 2.63$ & $0.474^{\dagger}$ \\
\hline
\end{tabular}

Notes: *Chi-Squared test and †Kruskal-Wallis test.

Abbreviations: CDVA, best-corrected distance visual acuity; ETDRS, Early Treatment Diabetic Retinopathy Study; ECD, endothelial cell density; IOP, intraocular pressure; CCT, central corneal thickness.

Table 2 Mean Change from Baseline to Six Weeks After Cataract Surgery

\begin{tabular}{|l|l|l|l|l|}
\hline & First Semester $(\mathbf{n}=\mathbf{1 0 2})$ & Second Semester $(\mathbf{n}=301)$ & Third Semester $(\mathbf{n}=327)_{\boldsymbol{p}^{-\mathbf{v a l u e}}{ }^{\dagger}}$ \\
\hline CDVA (ETDRS score) & $24.15 \pm 1.08$ & $22.40 \pm 1.11$ & $24.15 \pm 1.08$ & 0.2982 \\
ECD (cells/mm $\left.{ }^{2}\right)$ & $-542.72 \pm 49.97$ & $-478.27 \pm 32.63$ & $-433.02 \pm 31.18$ & 0.0678 \\
IOP $(\mathrm{mmHg})$ & $-0.35 \pm 0.46$ & $-0.04 \pm 0.26$ & $-0.76 \pm 0.24$ & 0.2176 \\
CCT $(\mu \mathrm{m})$ & $-2.28 \pm 1.85$ & $-1.61 \pm 1.48$ & $-0.01 \pm 1.54$ & 0.8073 \\
\hline
\end{tabular}

Notes: Data expressed as mean \pm standard deviation. †Kruskal-Wallis test.

Abbreviations: CDVA, corrected distance visual acuity; ETDRS, Early Treatment Diabetic Retinopathy Study; ECD, endothelial cell density; IOP, intraocular pressure; CCT, central corneal thickness.

was adjusted for gender and age. Results are shown in Table 4, with an emphasis on PCR with vitreous loss.

Multiple logistic regression confirmed the association between the group and the rate of surgical complications. Surgeries performed by residents in the first semester (L1) of training were 2.3 times more likely to involve complications than those done by third semester (L3) residents $(\mathrm{OR}=2.35$ [95\% CI: 1.32-4.19]). Similarly, surgeries done by residents in the second semester (L2) of training were 2.0 times more likely to have complications than those performed by thirdsemester (L3) residents ( $\mathrm{OR}=2.00$ [95\% CI: 1.28-3.12]). When the results were corrected for patient age, surgeries on individuals between 70 and 80 years of age were 2.0 times more likely to have complications than those younger than 60 years $(\mathrm{OR}=2.00$ [95\% CI: 1.02-3.92]); surgeries on individuals over 80 years of age were 2.3 times more likely $(\mathrm{OR}=2.31$ [95\% CI: 1.01-5.28]).

Multiple logistic regression also confirmed the association between the group and PCR: this complication was
1.9 times more frequent in surgeries performed by residents in the second semester of training than in those performed by third semester residents (OR $=1.93$ [95\% CI: 1.19-3.14]). Surgeries on patients between 70 and 80 years of age were 2.9 times more likely to involve PCR than those performed on patients younger than 60 years of age $(\mathrm{OR}=2.88$ [95\% CI: 1.25-6.62]).

Endothelial cell loss in each group was analyzed using multiple logistic regression adjusted for gender and age, as shown in Table 5.

No association was found between endothelial cell loss and gender or endothelial cell loss and group. However, multiple linear regression revealed a significant association between endothelial cell loss and age. Patients between 60 and 70 years of age lost an average of 164 more cells than those younger than 60 ( $p=0.007$ ); among patients between 70 and 80 years of age, an average of 230 more cells were lost than among patients under the age of $60(p<0.001)$. Among patients older than 80 years of age, 347 more cells

Table 3 Incidence of Surgical Complications in Each Semester of Phacoemulsification Training

\begin{tabular}{|l|l|l|l|l|}
\hline & First Semester $(\mathbf{n}=\mathbf{1 0 2})$ & Second Semester $(\mathbf{n}=301)$ & Third Semester $(\mathbf{n}=327)^{\mathbf{p}_{\text {-value }}}$ \\
\hline Total number of intraoperative events & $24(23.53 \%)$ & $63(20,93 \%)$ & $37(11.31 \%)$ & 0.001 \\
Number of PCRs with vitreous loss & $13(12.75 \%)$ & $51(16.9 \%)$ & $31(9.5 \%)$ & 0.015 \\
\hline
\end{tabular}

Note: †Kruskal-Wallis test.

Abbreviation: PCR, posterior capsule rupture. 
Table 4 Multiple Logistic Regression Analysis of Intraoperative Events Adjusted for Gender and Age

\begin{tabular}{|c|c|c|c|c|c|}
\hline & \multirow[t]{2}{*}{$\mathbf{N}$} & \multicolumn{2}{|c|}{ All Intraoperative Events } & \multicolumn{2}{|c|}{ Posterior Capsule Rupture with Vitreous Loss } \\
\hline & & Odds Ratio $(95 \% \mathrm{Cl})$ & $\mathbf{P}$ & Odds Ratio (95\% Cl) & $\mathbf{P}$ \\
\hline \multicolumn{6}{|l|}{ Semester } \\
\hline First & 102 & $2.35(1.32-4.19)$ & 0.004 & $1.38(0.69-2.77)$ & 0.368 \\
\hline Second & 301 & $2.00(1.28-3.12)$ & 0.002 & $1.93(1.19-3.14)$ & 0.008 \\
\hline Third & 327 & Reference & - & Reference & - \\
\hline \multicolumn{6}{|l|}{ Sex } \\
\hline Female & 382 & Reference & - & Reference & - \\
\hline Male & 348 & $0.98(0.66-1.45)$ & 0.922 & $0.96(0.62-1.49)$ & 0.867 \\
\hline \multicolumn{6}{|l|}{ Age } \\
\hline Under to 60 years & 115 & Reference & - & Reference & - \\
\hline $60 \mid-70$ years & 275 & $1.35(0.67-2.69)$ & 0.399 & $1.89(0.80-4.43)$ & 0.145 \\
\hline $70 \mid-80$ years & $27 \mid$ & $2.00(1.02-3.92)$ & 0.044 & $2.88(1.25-6.62)$ & 0.013 \\
\hline Over 80 years & 69 & $2.3 \mathrm{I}(\mathrm{I} .0 \mathrm{I}-5.28)$ & 0.047 & $2.36(0.85-6.57)$ & 0.099 \\
\hline
\end{tabular}

Abbreviation: $\mathrm{Cl}$, confidence interval.

were lost than among patients younger than $60(p<0.001)$. Table 6 shows the frequency of intraoperative events in the three groups.

PCR was the most frequent intercurrence observed in all three semesters: it occurred in $12.7 \%$ of the surgeries in the first semester (13/102), $16.9 \%$ of surgeries in the second

Table 5 Multiple Logistic Regression Analyses of Endothelial Cell Loss Adjusted for Gender and Age

\begin{tabular}{|c|c|c|c|}
\hline & \multirow[t]{2}{*}{$\mathbf{N}$} & \multicolumn{2}{|l|}{ Endothelial Cell Loss } \\
\hline & & Odds Ratio $(95 \% \mathrm{Cl})$ & $P$ value \\
\hline \multicolumn{4}{|l|}{ Semester } \\
\hline $\begin{array}{l}\text { First Semester } \\
\text { Second } \\
\text { Semester } \\
\text { Third Semester }\end{array}$ & $\begin{array}{l}102 \\
301 \\
327\end{array}$ & $\begin{array}{l}-73.26(-186.50 \text { a } 39.98) \\
-12.88(-95.01 \text { a } 69.22) \\
\text { Reference }\end{array}$ & $\begin{array}{l}0.204 \\
0.758 \\
-\end{array}$ \\
\hline \multicolumn{4}{|l|}{ Sex } \\
\hline $\begin{array}{l}\text { Female } \\
\text { Male }\end{array}$ & $\begin{array}{l}382 \\
348\end{array}$ & $\begin{array}{l}\text { Reference } \\
47.75(-27.8|-+| 23.3 \mid)\end{array}$ & $\begin{array}{l}- \\
0.215\end{array}$ \\
\hline \multicolumn{4}{|l|}{ Age } \\
\hline Up to 60 years & 115 & Reference & - \\
\hline $60 \mid-70$ years & 275 & $-163.52(-281.86-+45.18)$ & 0.007 \\
\hline $701-80$ years & 271 & $\begin{array}{l}-230.00(-344.77- \\
-115.24)\end{array}$ & $<0.001$ \\
\hline Over 80 years & 69 & $\begin{array}{l}-346.61(-499.21- \\
-194.01)\end{array}$ & $<0.001$ \\
\hline
\end{tabular}

Abbreviation: $\mathrm{Cl}$, confidence interval. semester (51/301), and $9.5 \%$ of surgeries in the third semester (31/327). Incision burn occurred only in surgeries performed in the first semester. There were no cases of endophthalmitis in our study. Table 7 shows the frequency of reoperations on or before the forty-fifth postoperative day in each group, including vitrectomy, trabeculectomy, and keratoplasty.

There were no statistically significant differences among groups regarding reinterventions $(\mathrm{p}=0.213)$.

\section{Discussion}

Phacoemulsification is a key surgical technique learned by ophthalmology residents as part of their training. Residency programs differ in their teaching techniques and training processes. Residents inevitably develop their own skills at an individualized pace; nevertheless, ophthalmology residency training programs should have specific training guidelines and provide a minimum number of surgeries to guarantee that residents will properly develop competency in phacoemulsification. A review of teaching methods demonstrated that complication rates decline after a resident performs an average of 70 surgeries. ${ }^{20}$ The ophthalmology residency program at UNICAMP follows the processes used by other Brazilian programs, in which surgical techniques are taught in the second year of the three-year program. Surgical training begins with cataract surgery based on the extracapsular technique, followed by step-by-step phacoemulsification training. Residents are supervised by a senior surgeon in all surgeries. 
Table 6 Frequency of Intraoperative Events

\begin{tabular}{|c|c|c|c|c|}
\hline & First Semester $(n=102)$ & Second Semester $(n=30 I)$ & Third Semester $(n=327)$ & $p$-value ${ }^{t}$ \\
\hline PCR with vitreous loss & 8 & 44 & 29 & 0.197 \\
\hline PCR and aphakia & 3 & 1 & 2 & 0.420 \\
\hline PCR and dropped nucleus & 2 & 6 & 0 & 0.065 \\
\hline Incision burn & 3 & 0 & 0 & 0.073 \\
\hline Descemet's membrane detachment & 3 & 8 & I & 0.066 \\
\hline Argentinian flag sign & 0 & 2 & I & 0.554 \\
\hline Iris herniation & 3 & 2 & 2 & 0.420 \\
\hline Zonular dehiscence & 2 & 0 & 2 & 0.554 \\
\hline Total & 24 & 63 & 37 & \\
\hline
\end{tabular}

Note: †Fischer's exact test.

Abbreviation: PCR, posterior capsule rupture.

Table 7 Frequency of Reoperations

\begin{tabular}{|l|l|l|l|l|}
\hline & First Semester $(\mathbf{n}=1$ 02) & Second Semester $(\mathbf{n}=301)$ & Third Semester $(\mathbf{n}=327)^{\mathbf{p}^{-\mathbf{v a l u e}} \mathbf{H}^{\dagger}}$ \\
\hline Vitrectomy & 2 & 8 & 3 & 0.486 \\
Trabeculectomy & 0 & 2 & 1 & 0.073 \\
Keratoplasty & 0 & $\mathrm{I}$ & 0 & 0.666 \\
Secondary IOL implantation & 0 & $\mathrm{I}$ & 0 & 0.666 \\
Total & 2 & 12 & 4 & \\
\hline
\end{tabular}

Note: †Fischer's exact test.

Abbreviation: IOL, intraocular lens.

By the end of the first semester of surgical training (the end of the second year of the residency), residents are expected to be able to perform incisions, capsulorhexis, hydrodissection, hydrodelineation, and intraocular lens implantation. These skills are expected to improve over the course of the third year of the residency, as is residents' ability to perform phacoemulsification of the nucleus itself.

For a detailed evaluation of the residents' surgical outcomes and the learning curve they experienced, specific parameters were considered in this study. CDVA before and after surgery was compared, and, as expected, it improved significantly in all groups. However, there were no significant differences between the groups. Though preoperative endothelial parameters did not differ significantly between the groups, the comparison of postoperative data revealed trends of less endothelial cell loss as the training process progressed. It is likely that, with a higher number of surgeries performed by the same group of residents, statistical significance would be achieved.

As expected, the rate of complications decreased as residents progressed in their program. Overall rates of complications reported in the literature range from $1.8 \%$ to $27.4 \%$ in residency programs. ${ }^{4,5,8,21,22}$ When compared to the literature, the rate of complications among the second-year residents at UNICAMP was relatively high, and third-year residents experienced rates more similar to those of other programs. ${ }^{4,5,8,21,22}$ A comparison of types of complications over the course of the program revealed a substantial decrease in more serious complications such as PCR, aphakia, zonular dehiscence and dislocation of the lens nucleus to the vitreous cavity.

An interesting finding was that residents in the second semester (L2) of surgical training exhibited a higher frequency of complications than residents in the first semester (L1), particularly in terms of vitreoretinal events (PCR, vitreous loss, aphakia, and dislocation of the lens to the vitreous cavity). This finding has also been reported in previous studies. ${ }^{23,24}$ In addition, there was a substantial increase in the need for re-operations among L2 patients relative to L1 patients, which reflects the severity of the complications. We attribute this finding to a possible feeling of overconfidence demonstrated by residents after their completion of the first semester of initial training without many intraoperative events. It may be an attempt to perform the procedures more independently of the senior surgeon, akin to learning how to ride a bike and falling when the training wheels come off. Similarly, it is also 
plausible that supervisors' overconfidence in the trainees' skills at this point in the learning process reduce the supervisors' frequency of interventions, whether they be verbal or technical. The current study helps us to understand that this trend may be improved through increased attention and intervention from supervisors at a specific point in the learning process. Because students tend to experience an increase in complications at a specific point, this period may require changes to the cataract teaching program in order to reduce surgical complications. Furthermore, we believe that training on surgical simulators, which are as yet unaffordable for our institution, could help to improve this trend.

We also observed an increased risk of complications and remarkable endothelial cell loss in patients over 70 years of age. This finding reinforces concerns that postponing surgical indication time increases rates of complications, since the aging process may lead to more difficult surgical procedures. At our institution, the main parameters use to determine surgical indication are LOCS III cataract classification, the impact of cataracts on patient quality of life, and corrected visual acuity. Because of the higher rate of complications and greater endothelial cell loss found in older patients, we believe age should be an important parameter in surgical indication, even when cataracts exhibit relatively little density or limited loss of visual acuity.

Some limitations of this study may also be noted. Additional parameters not evaluated herein, such as axial length, anterior chamber depth, phacoemulsification time, average ultrasound power, and cumulative dissipated energy would enrich an analysis such as this one. The lack of information on subjective patient satisfaction, resident feedback, and a description of the resident's level of involvement in each surgery, are limitations of the study. Knowing whether the surgery was entirely or only partially performed by the resident would enrich the study, but, unfortunately, this specific data was not recorded. Additionally, the use of different phacoemulsification machines was not compared, and no correlations were measured between the rate of complications rate and the technique that was used (the divide and conquer technique versus the stop and chop technique). Wet lab or simulator training were not yet available in our residency program at the time of this study. We believe that this important training step would be useful for beginners to achieve surgical skills and confidence. Some studies in the literature have reported the use of wet labs to begin residents' surgical training, ${ }^{8}$ while others have reported the use of simulators and virtual-reality simulation. ${ }^{25-29}$ Authors have reported evidence of higher success rates and lower rates of complications when these learning strategies are added. Such methods may improve the learning curve experienced by residents, and may reduce surgical complications; however, they cannot fully replace real surgical experience, which is an inherent and integral part of residency training. Thus, when we can include wet lab training in animal, simulators, and virtual-reality simulation in our residency program, the baseline evidence provided by this study will allow for comparisons and a better understanding of their impact on phacoemulsification training. For the next studies, we also consider the use of cataract surgery competency grading tools.

From 1991 to 2017, cataract learning curve studies were rare and largely focused on rates of complications; the sample sizes ranged from 40 to 755 eyes, mean 338.4 +- 242.5 operated eyes (95\% CI: 191.8-484.9). ${ }^{2-8,10,22,23}$ The largest study, performed by Bhagat et al, ${ }^{7}$ assessed rates of complications in surgeries performed by five different resident groups over the course of five years. Moreover, few studies have evaluated important-related parameters such as pachymetric variation ${ }^{13}$ or endothelial cell loss. ${ }^{14}$ The present study assessed a consistently larger number of surgeries performed by the same group of residents and has also provided a comprehensive analysis of ocular parameters.

We believe that our study's greatest strength is its analysis of data from a group of 10 residents over the course of their phacoemulsification training period (18 months), during which a substantial number of surgeries (730) were performed. Furthermore, with the advent of surgical simulators, information on surgical complications and outcomes among a given group of residents will prove useful in determining how surgical simulators should be applied. This data will allow for comparisons to residents who are able to practice on simulators. These comparisons will enable an assessment of the impact of this new technology on student learning.

\section{Conclusion}

This study demonstrated that the rate of complications in cataract surgery is relatively high among residents, especially in the second semester of training and in cases of elderly patients. Even so, we observed that the loss of endothelial cells decreased during residency training, a fact that indirectly shows improvement of the technique. Close, careful and intense supervision is crucial to 
a secure training process for residents and patients alike. Supervisors may need to refocus their attention when, after succeeding in the initial steps of the training process, residents may exhibit an amount of confidence that is not yet proportional to their abilities to recognize risks, overcome difficulties, and avoid severe complications. Additionally, as supervisors gain more confidence in a given trainee's performance, they may provide fewer interventions. As noted, this is precisely the moment that the most serious complications tend to occur.

As life expectancy raises, a consistent increase in the number of cataract surgeries is expected, as is the number of surgeons able to safely perform those procedures. Thus, a proper regard for the cataract surgery training process is essential to guarantee skillful surgeons, well performed surgeries, better outcomes and visual rehabilitation.

A better understanding of learning processes, rates of complications, and the most critical steps to achieve surgical skills may guide educators toward improved teaching strategies for cataract surgery.

\section{Abbreviations}

CDVA, corrected distance visual acuity; IOP, intraocular pressure; ECD, endothelial cell density; CCT, central corneal thickness; PCR, posterior capsule rupture; ECCE, extracapsular cataract extraction.

\section{Data Sharing Statement}

The datasets used and/or analysed during the current study are available from the corresponding author on reasonable request.

\section{Ethics Approval}

This study was performed after approval from the local research ethics committee (University of Campinas Ethics Committee) and was conducted in accordance with the tenets of the Declaration of Helsinki and current legislation on clinical research.

\section{Funding}

The authors declare that they have no funding.

\section{Disclosure}

The authors declare no financial or non-financial interest conflicts of interest for this work.

\section{References}

1. Leaming DV. special report practice styles and preferences of ASCRS members - 2003 survey. J Cataract Refract Surg. 2004. doi:10.1016/j.jcrs.2004.02.064

2. Taravella MJ, Davidson R, Erlanger M, Guiton G, Gregory D. Characterizing the learning curve in phacoemulsification. $J$ Cataract Refract Surg. 2010;37(6):1069-1075. doi:10.1016/j.jcrs.2010.12.054

3. Tarbet KJ, Mamalis N, Theurer J, Jones BD, Olson RJ. Complications and results of phacoemulsification performed by residents. $J$ Cataract Refract Surg. 1995;21(6):661-665. doi:10.1016/S0886-3350(13)80562-7

4. Allinson RW, Metrikin DC, Fante RG. Incidence of vitreous loss among third-year residents performing phacoemulsification. Ophthalmology. 1992;99(5):726-730. doi:10.1016/S0161-6420(92) 31904-9

5. Bhagat N, Nissirios N, Potdevin L, et al. Complications in resident-performed phacoemulsification cataract surgery at New Jersey medical school. Br J Ophthalmol. 2007;91(10):1315-1318. doi:10.1136/bjo.2006.111971

6. Cruz OA, Wallace GW, Gay CA, Matoba AY, Koch DD. Visual results and complications of phacoemulsification with intraocular lens implantation performed by ophthalmology residents. Ophthalmology. 1992;99(3):448-452. doi:10.1016/S0161-6420(92) 31954-2

7. Hashemi H, Mohammadpour M, Jabbarvand M. Incidence of and risk factors for vitreous loss in resident-performed phacoemulsification surgery. $J$ Cataract Refract Surg. 2013;39(9):1377-1382. doi:10.1016/j.jcrs.2013.03.028

8. Lee J, Hou C, Yang M, Kuo J. A different approach to assess resident phacoemulsification learning curve: analysis of both completion and complication rates. Eye. 2009;23(February 2008):683-687. doi:10.1038/sj.eye.6703103

9. Nagashima RJ. Decreased incidence of capsule complications and vitreous loss during phacoemulsification in eyes with pseudoexfoliation syndrome. J Cataract Refract Surg. 2004;30(1):127-131. doi:10.1016/S0886-3350(03)00465-6

10. Rutar T, Porco TC, Naseri A. Risk factors for intraoperative complications in resident-performed phacoemulsification surgery. OPHTHA. 2008;116(3):431-436. doi:10.1016/j.ophtha.2008.10.028

11. Al-Jindan M, Almarshood A, Yassin SA, Alarfaj K, Mahmood AA, Sulaimani NM. Assessment of learning curve in phacoemulsification surgery among the Eastern Province ophthalmology program residents. Clin Ophthalmol. 2020;14:113-118. doi:10.2147/OPTH. S241250

12. Gharaee H, Jahani M, Banan S. A comparative assessment of intraoperative complication rates in resident-performed phacoemulsification surgeries according to najjar-awwad preoperative risk stratification. Clin Ophthalmol. 2020;14:1329-1336. doi:10.2147/ OPTH.S252418

13. Lhuillier L, Jeancolas AL, Renaudin L, et al. Impact of Ophthalmic Surgeon Experience on Early Postoperative Central Corneal Thickness After Cataract Surgery. Cornea. 2017;36(5):541-545.

14. O'Brien PD, Fitzpatrick P, Kilmartin DJ, Beatty S. Risk factors for endothelial cell loss after phacoemulsification surgery by a junior resident. $J$ Cataract Refract Surg. 2004;30(4):839-843. doi:10.1016/S0886-3350(03)00648-5

15. Teoh LS, Foo SW, Mansurali VN, Ang EL, Bastion MC. Evaluation of corneal endothelial cell loss after uncomplicated phacoemulsification cataract surgery with intracameral phenylephrine. Asia Pac J Ophthalmol. 2017;6(4):318-323. doi:10.22608/APO.2016206

16. Salvi SM, Soong TK, Kumar BV, Hawksworth NR. Central corneal thickness changes after phacoemulsification cataract surgery. J Cataract Refract Surg. 2007;33(8):1426-1428. doi:10.1016/j. jcrs.2007.04.010 
17. Hayashi K, Hayashi H, Nakao F. Risk factors for corneal endothelial injury during phacoemulsification. J Cataract Refract Surg. 1996;22 (8):1079-1084

18. Zetterstrom C, Laurell C. Comparison of endothelial cell loss and phacoemulsification energy during endocapsular phacoemulsification surgery. J Cataract Refract Surg. 1995;21(1):55-58.

19. Melega MV, Alves M, Pessoa R, et al. Safety and efficacy of intracameral moxifloxacin for prevention of post-cataract endophthalmitis: randomized controlled clinical trial. J Cataract Refract Surg. 2018;45(3):343-350. doi:10.1016/j.jcrs.2018.10.044

20. Kaplowitz K, Yazdanie M, Abazari A. A review of teaching methods and outcomes of resident phacoemulsification. Surv Ophthalmol. 2018;63(2):257-267. doi:10.1016/j.survophthal.2017.09.006

21. Corey RP, Olson RJ. Surgical outcomes of cataract extractions performed by residents using phacoemulsification. $J$ Cataract Refract Surg. 1992;24(1):66-72. doi:10.1016/S0886-3350(98)80076-X

22. Lynn MJ, Cherwek DH, Srivastava SK. The resident surgeon phacoemulsification learning curve. Arch Ophthalmol. 2015;125 (9):1215-1219.

23. Woodfield AS, Gower EW, Cassard SD, Ramanthan S. Complication rates of second- and third-year ophthalmology residents a 5-year comparison. OPHTHA. 2011;118(5):954-958. doi:10.1016/j. ophtha.2010.08.047
24. Mangan MS, Atalay E, Arıcı C, Tuncer İ, Bilgeç MD. Comparison of different types of complications in the phacoemuls cation surgery learning curve according to number of operations performed. Turk J Ophthalmol. 2016;46:7-10. doi:10.4274/tjo.83788

25. Thomsen AS, Kiilgaard JF, Kjærbo H, Cour M, Konge L. Simulationbased certification for cataract surgery. Acta Ophthalmol. 2015;93 (5):416-421. doi:10.1111/aos.12691

26. Thomsen AS, Bach-holm D, Kjærbo H, et al. Operating room performance improves after proficiency-based virtual reality cataract surgery training. Ophthalmology. 2016;1-8. doi:10.1016/j. ophtha.2016.11.015

27. Thomsen AS, Smith P, Subhi Y, et al. High correlation between performance on a virtual- reality simulator and real-life cataract surgery. Acta Ophthalmol. 2016;95:1-5. doi:10.1111/aos.13275

28. Thomsen AS, Subhi Y, Kiilgaard JF, Cour M, Konge L. Update on simulation-based surgical training and assessment in ophthalmology a systematic review. Ophthalmology. 2015. doi:10.1016/j. ophtha.2015.02.028

29. Belyea DA, Brown SE, Rajjoub LZ. Influence of surgery simulator training on ophthalmology resident phacoemulsification performance. J Cataract Refract Surg. 2011;37(10):1756-1761. doi:10.1016/j. jcrs.2011.04.032
Clinical Ophthalmology

\section{Publish your work in this journal}

Clinical Ophthalmology is an international, peer-reviewed journal covering all subspecialties within ophthalmology. Key topics include: Optometry; Visual science; Pharmacology and drug therapy in eye diseases; Basic Sciences; Primary and Secondary eye care; Patient Safety and Quality of Care Improvements. This journal is indexed on PubMed
Dovepress

Central and CAS, and is the official journal of The Society of Clinical Ophthalmology (SCO). The manuscript management system is completely online and includes a very quick and fair peer-review system, which is all easy to use. Visit http://www.dovepress.com/ testimonials.php to read real quotes from published authors. 